\title{
Translational research policies: disruptions and continuities in biomedical innovation systems in Austria, Finland and Germany
}

\author{
Etienne Vignola-Gagné • Elina Rantanen • \\ Daniel Lehner • Bärbel Hüsing
}

Received: 20 March 2012 / Accepted: 4 December 2012 /Published online: 29 December 2012

(C) The Author(s) 2012. This article is published with open access at Springerlink.com

\begin{abstract}
Increasing the rate of biomedical research that is relevant to clinical innovation has been an intensifying concern of the research community and of policy-makers. In response, some of these actors have recently promoted varied approaches they label as translational research (TR) and translational medicine. This movement started in the USA in the early 1990s, and has since evolved to encompass large and ambitious initiatives. Its advocates contend that the productivity of biomedical innovation systems can be bolstered by: (1) the extension of largescale development collaborations; (2) the strengthening of clinical experimental platforms; (3) training and supporting dedicated human capital; (4) achieving higher collective coordination of research teams than was previously common practice. In this paper, we examine to which extent these objectives have been put into practice by communities of biomedical actors and policymakers, by characterizing current translational initiatives in three European countries-Austria, Finland and Germany. This research draws on an analysis of
\end{abstract}

\section{E. Vignola-Gagné • B. Hüsing}

Competence Center Emerging Technologies, Fraunhofer Institute for Systems and Innovation Research ISI, Breslauer Str. 48,

76139 Karlsruhe, Germany

\section{E. Vignola-Gagné $(\bowtie)$}

Life-Science-Governance research platform, Department of Political Science, University of Vienna, Dr-Karl-Lueger-Ring 1, 1010 Vienna, Austria

e-mail: etiennevg@gmail.com

E. Rantanen

Department of Social Research,

University of Helsinki, Unioninkatu 37,

Helsinki, P.O.Box 54, 00014, Finland

D. Lehner

Department of Sociology, Institute for Advanced Studies,

Stumpergasse 56 ,

1060 Vienna, Austria policy documents and 26 semi-structured interviews conducted with policy-makers and TR advocates from these countries. Traditions of science and technology policy-making in each country have made them differentially receptive to the TR movement. German biomedical actors have most fully put into practice TR propositions, while Finland has seen policy-level debate of the notions but little in the way of concrete implementation and Austria appears to be a middle case.

Keywords Translational research - Translational medicine . Innovation policy · Genomics · Clinician-scientists ·

Pharmaceutical innovation crisis

\section{Introduction}

In the context of the Human Genome Project, high expectations have been raised that the face of clinical care would be changed drastically by the short-term arrival of improved diagnostics and therapeutics developed by harnessing -omics platforms. Most notably at the moment, expectations have run high that efforts in the discovery and validation of biomarkers could provide new tools for rational drug development, for diagnostic interventions and for tailoring treatments based on individuals' molecular make-up ("personalised medicine") (Yap et al. 2010). Despite their potential for clinical innovation, few new interventions drawing directly from these advances have in fact reached regulatory approval, and less still have been successfully adopted in the clinic (Pisano 2006; Martin et al. 2009; Janssens and van Duijn 2010; Swinney and Anthony 2011; Anonymous 2012; Hoelder et al. 2012). Commentators have thus, in recent years, decried a situation where the biomedical field would be sitting on a gold mine of basic post-genomic research just waiting to be properly exploited into clinical innovation. 
A parallel, but more recent development has also contributed to shaping perceptions that investments in biomedical research are increasingly disconnected from improvements in clinical practice and, especially, in therapeutic modalities. With a landmark 2004 report of the US Food and Drug Administration, biomedical actors worldwide started discussing the possibility of an impending crisis of innovation in the pharmaceutical industry sector (FDA 2004). Large pharmaceutical companies have recently had to engage in heavy personnel cuts, because of a historical conjuncture where the blockbuster products, usually drugs, which provided them with most of their revenues are falling off patent without having been gradually replaced with new such blockbusters (Macllwain 2011; Mittra et al. 2011). Yet, advances in postgenomic platforms were expected to replenish the sources of innovation in pharmaceutical research and technology development (RTD). Taken together, these problems seem to indicate the need for new means to exploit genomic knowledge, with an aim to deliver the promises of genomic research by improving clinical care to patients and thus justify the large investments made in genomics projects to citizens; and provide the pharmaceutical sector with new innovation platforms to get out of crisis.

With the goal to increase the relevance of biomedical research for clinical innovation, a number of actors in biomedicine and policy-making have argued for the expansion of efforts made in the area of applied pre-clinical laboratory research and early clinical research. Advocates of this view have promoted the concept of a field of Translational Research (or Translational Medicine or Translational Science; abbreviated to TR here), with dedicated expertise focused on mobilizing basic research results and clinical experience in the development of new or improved clinical interventions. TR propositions have been characterized by a desire to link together biological, engineering, biochemistry and clinical competences to provide integrated academic or public-private RTD pipelines. It is perhaps most appropriate to talk of TR as a reform movement within biomedical research (following Milne and Kaitin 2009), one that aims to change both researchers' experimental practices and policy-makers' and academic administrators' organisational models (Gaisser et al. 2009). There has been intense discussion of these new propositions within the biomedical community (Nathan 2002; Weissmann 2005; Khoury et al. 2007; Wehling 2008; Woolf 2008; Milne and Kaitin 2009; Wehling 2010; Marincola 2011), and a number of welladvertised and well-funded new institutions that bear the label of TR have recently been established (Zerhouni 2005; NCI 2007; Borstein and Licinio 2011; Collins 2011; Kupferschmidt 2011; Shahzad et al. 2011; von Roth et al. 2011). Despite all of this activity, it is still unclear to which extent the propositions of the TR movement have effectively led to concrete changes in both the daily experimental and organisational practices of biomedical actors and the orientations of those state-formulated policies that frame innovation activities. This article examines the recent policies and institutional initiatives of three European countries to answer this question.

\section{Understanding change in biomedical innovation: a proposed analytical grid}

Making academic research activities more relevant to industry and civil society has been a recurring goal of science, technology and innovation policy makers since the 1980s (Guston 2000; Nowotny et al. 2001; Van der Weijden et al. 2012). In the biomedical field more specifically, typical measures that have been put into place by state- and institution-level policymakers to achieve this goal have included: the promotion of academic entrepreneurship for the creation of specialized biotechnology firms that can engage in RTD work (Corolleur et al. 2004; Ebers and Powell 2007; Grimaldi et al. 2011); the promotion of technology transfer activities, often through the creation of dedicated offices in universities for stepping up patent filing and facilitating contract or cooperative research with industry (Colyvas 2007; Trippl and Tödtling 2008); the support of mixed research networks including both academic and private organisations (Stuart et al. 2007). Until recently, policy-level discussions about the promotion of health intervention development work in biomedicine have often revolved specifically around these measures (Pisano 2006; Martin et al. 2009; Lander and Atkinson-Grosjean 2011).

The emergence of a discussion around TR model has brought to the foreground a different set of issues in the search to improve the productivity of biomedical innovation systems then those discussed in the paragraph above. There has been a multitude of claims and propositions for reform made using the TR label. In this section, we present three core claims that have recurrently been put forward in editorials, commentaries but also policies about TR. Using these categories, we aim to capture the type of scientific and institutional changes advocated in discussions about TR. Together, they form the basis for what we would here call the "TR model". We will refer to the "TR movement" to refer to this large and unorganised group of actors that have actively advocated the TR model as a means to improve biomedical innovation systems.

\section{Experimental platforms and research practices}

Proponents of the TR model maintain that biomedical innovation should make a central place to experimental practices conducted in clinical contexts. Some representations of biomedical innovation have had a tendency to treat clinical research as simply a means to validate therapeutic hypotheses that originate in laboratory experiments using animal models, cell cultures or collections of biospecimen, for example 
(Nightingale and Martin 2004; Keating and Cambrosio 2012). Instead TR advocates maintain that clinical research and clinical care are practices productive of experimental knowledge in their own right, that they are an important source of hypotheses and data, and that they need to be put at the foreground of biomedical innovation to improve productivity (Nathan 2002; Coller 2008; Wehling 2008; CIHR 2011; Marincola 2011). The experimental fecundity of clinical research is argued to be especially well visible in areas such as therapeutic research into targeted anti-cancer agents. There, new developments in "biology-led clinical trials", for example, transform early clinical studies into complex experimental platforms that combine simultaneous and interdependent clinical and laboratory areas (Hoelder et al. 2012). Analysts of biomedical policy themselves have indeed commented that hospitals and clinics were "hidden innovation systems", because these sites of knowledge production have often been left out of the dominant representations of innovation in the field (Lander and Atkinson-Grosjean 2011). As such, academic medicine centres and university clinics have been argued to form central institutions in TR initiatives (Zerhouni 2005; FitzGerald 2009).

There is a second aspect to the arguments about the experimental platforms and research practices that would be most conducive to TR. Advocates of the approach have often contended that TR projects are best conducted by large-scale inter-disciplinary and inter-organisational collaborations. The development of complex new health interventions (such as small molecule drugs and biologics, advanced therapy medicinal products such as stem-cell treatments, diagnostics based on gene or genome-wide sequencing technologies) necessitate the successful combination of a variety of competences, experimental equipments and institutional routines, in addition to close interactions between laboratory and clinic (Hörig et al. 2005; Khoury et al. 2007; NCI 2007; Anonymous 2008; FitzGerald 2009; Silber 2010; Collins 2011; Williams et al. 2012). Expertise in animal models, in vitro cell cultures, typing of tissue samples, pharmaceutical chemistry in all of its ramifications, including mass screening of compound libraries, medical imaging, are all mobilized in the development of a new drug, for example. Many of these experiments have to comply with strict regulatory standards, or necessitate costly investments in specialised equipment not commonly found in academic institutions. While these experimental approaches are commonly combined by the pharmaceutical industry, similar efforts in an academic environment are mostly novel.

\section{Training and human capital}

Interdisciplinary brokers are single individuals that can legitimately engage in the practices of multiple scientific disciplines or organisations, and assist colleagues belonging to one of these social groups to exchange with members of the other (Calvert 2010). New professional interdisciplinary identities, institutionalized through dedicated training programmes, can help to stabilize emerging fields of research and the networks that enact them. Given the high interdisciplinary and interorganisational character of TR, it should come as no surprise that the emergence of this policy narrative has been accompanied by claims of professional jurisdiction. Particularly, clinician-scientists have claimed a privileged expertise in coordinating and leading TR projects, resting on their dual expertise in both experimental and clinical care practices (for primary literature presenting those claims, see: Nathan 2002; Coller 2008; Borstein and Licinio 2011; von Roth et al. 2011; for social science analyses, see Wilson-Kovacs and Hauskeller 2012). The potential authority of this interdisciplinary human capital is compounded by the reunion within single TR projects of actors with a variety of backgrounds, each bringing different frameworks for experimental practice and for evaluating what counts as "good translational research" (see Wainwright et al. 2009; Morgan et al. 2011). It can thus be expected that other types of interdisciplinary brokers, beside from clinician-scientists, can also be encountered in actual TR projects.

\section{Coordination and policy}

The large and complex projects of the TR enterprise necessitate more management and coordination than what is typical for academic research networks. Consensus and a sophisticated division of labour are necessary to diligently work on one single development project. This was true of biomedical innovation before, but it is even more so in public TR networks, where individual members of the consortium are likely to find greater academic recognition by engaging in curiosity-driven projects than by engaging in the development work required by the consortium (Anonymous 2008). Strategic planning may be required to make sure that the multiple actors composing biomedical innovation systems collectively carry over new knowledge and technologies to development phases, even when the principal investigators responsible for these advances are not interested in this work. To ensure a high level of coordination in TR initiatives, commentators have devised elaborated project planning methods (Wehling 2010; Hoelder et al. 2012). There has also been a proliferation of models and representations of the innovation process which assign roles and functions to various groups of academic professionals, essentially creating plans for sophisticated divisions of translational labour (Khoury et al. 2007; NCI 2007). Finally, there has been mounting argumentation that a new group of professionals are needed to lead TR projects, individuals that have less capacities for creativity and curiosity than for the management and coordination of large teams (Harrigan and Emery 2010; Borstein and Licinio 2011). Even patient organisations or charities have felt that they might have to fill such coordination roles, with the realisation "there is no one paid to spend $100 \%$ 
of his or her time following a problem from start to finish. This creates a leadership gap, where foundations need to step in and act as the focal point for the research" (Institute of Medicine 2009: 23). This argument demonstrates a broad need for coordination skills, one that may be filled by a number of new or unexpected professional groups or organisations.

It is also under this category that it is most appropriate to discuss the impacts that policies formulated by state agencies can have on the initiatives and behaviour of biomedical actors themselves. While RTD strategies are often put into practice by building new institutions or establishing incentives for certain types of research (funding programmes and tax breaks), an important aspect of policies is also to provide collective priorities and shared means of action (Gottweis 1998; Fischer 2003). In other words, RTD strategies provide models, blueprints or directions for organising collaborations between different groups. Tellingly, political scientists have talked of these organising effects of policy-making as instances of "coordinative discourse" (Schmidt 2012).

\section{Materials and methods}

An analysis of initiatives and policies dealing with TR in Austria, Finland and Germany was completed between September 2010 and February 2011. Data collection focused on a document analysis of "policy formulations", most notably governmental white papers and approximately 200 editorials, commentaries and reviews about TR published in peerreviewed biomedical journals. The subset of policy and initiatives selected for analysis and presented in the "Results" section were clearly labelled by their promoters as instances of TR.

Additionally, semi-directed interviews were conducted with policy-makers and biomedical researchers that were leading voices in TR discussions or initiatives in their country (nine in Austria, five in Finland and 12 in Germany - see the Annex for the list of respondents). Interviews and documents were coded and analysed following an analytical grid that aimed to capture the dimensions of the historical development of the TR discussion, organisational shaping and coordination issues in TR projects, and the features of the experimental practices mobilized in developing a new health intervention. As part of our broader research programme, semi-directed interviews and document analyses were also conducted at the level of networks supported by the European Commission (nine interviews) and other important TR institutions across Europe, as well as in the USA (19 interviews). This set of data is not the focus of the analysis presented in this paper, yet this material also informs our broader understanding of how TR issues are developing in biomedical policy.

\section{Results}

Experimental platforms and research practices

In all three countries under study here, new institutions have been put into place with the goals to take the propositions of the TR movement to practice. In this section, notable initiatives from each country will be detailed, acting as case studies to track the potential changes that could be observed at the level of local RTD practices.

\section{Austria}

Two initiatives seem to lead developments in terms of TR in Austria. The first, the OncoTyrol consortium, brings together more than 36 pharmaceutical and other private sector entities with a core of three institutes from the Tyrol region: UMIT (The Health and Life Sciences University-with its bioinformatics and health technology assessment divisions), the Medical University Innsbruck (with participation from departments in experimental cell biology, pharmacology) and Biocenter Innsbruck (including departments in molecular pathophysiology, bioinformatics). The consortium is coordinated through a private limited liability company. It is funded at the level of $24 \mathrm{M} €$ for the period 2008-2012 and $13.5 \mathrm{M} €$ from 2012 to 2015 . Funding is provided by governmental sources $(50 \%)$, participating universities $(5 \%)$ and industrial partners $(45 \%)$. The consortium involves about 85 researchers and technicians within 24 projects led by the various core institutions presented above. Research efforts are directed towards: the pathophysiology of cancer, notably tumour growth and anti-tumour immunity; developing tools in bioanalytics for improved biomarker discovery and validation; the discovery and validation of biomarkers for diagnostic purposes, for patient stratification in clinical trials and for drug development; bioinformatics and system biology capacities to support the other objectives and finally, health technology assessment, public health and economic modelling tools that are relevant for decision-making in oncology translational efforts. The experimental systems involved thus include tissue samples analysis and typing, in vitro cell cultures, in silico modelling of drug action and molecular binding and cohort studies for biomarker validation, but also the tools used in appraising the health politics and economic dimensions relevant in the development of new health interventions.

The second initiative of note is the Anna-Spiegel Centre (ASC), a new research facility at the Medical University of Vienna (MUV) bringing together its foremost research groups. This centre was founded as a means to better support existing research groups at the MUV and to provide them with improved "Core facilities". The goal given here is to support efforts within the MUV that foster exchanges 
between clinical questions and related research efforts, as well as the feedback of new findings into medical treatment. This is accomplished by an architecture that supports interaction, providing easy access to a variable range of instruments within the individual researcher's bench, allowing to easily switch between various experimental systems and intellectual tasks. Costs for the building (41 M€) were shared between the City of Vienna and the Austrian Ministry for Science and Technology. This new building provides improved infrastructures for MUV research teams, but they are financed as before mostly through external funding, including principal investigator grants.

In terms of experimental practices, the specific OncoTyrol project we examined involved many exchanges between laboratory and clinical contexts. The therapeutic modality being investigated had gone through a number of exploratory clinical studies that had contributed to shaping further manipulations on cell cultures and in animal models. Clinicians however were not leaders within the project. Project leaders had also stricken collaborations with local biotechnology firms to access good manufacturing practicecompliant facilities, for example, extending the scope of the project towards development practices.

Looking at the ASC case, it is striking that this initiative did not bring substantial change to the research already done at the MUV. The formal mission of research groups remains to perform research that can solve problems clinicians face daily, a continuation of the traditional agenda of experimental medicine. The scope of research projects appears to closely follow the sum of competences possessed within the groups centred around principal investigators. No large-scale collaborations were institutionalized through the creation of this separate centre, and there did not appear to be provisions made to support the development of complex health interventions such as therapeutics. It must also be noted that a large portion of the research teams conduct curiosity-driven projects on aspects of human molecular pathophysiology with no immediate relevance for clinical innovation. Although some of the research performed at the centre is clearly driven by clinical practice, it is interesting to notice that the physical separation of research teams from clinical care facilities established by the creation of the ASC runs counter to the current TR trend to combine these two functions in single locations.

\section{Finland}

The Institute for Molecular Medicine Finland (FIMM) is the flagship initiative for TR in Finland. It was formed as a joint venture of the University of Helsinki, the Hospital District of Helsinki and Uusimaa, the National Institute for Health and Welfare, the VTT Technical Research Centre of Finland, as well as the European Molecular Biology Laboratory. Various FIMM researchers are involved in European initiatives funded by the Innovative Medicines Initiative and the European Strategy Forum on Research Infrastructures (including the European Advanced Translational Research Infrastructure in Medicine, Biobanking and Biomolecular Resources Research Infrastructure and ELIXIR - involved in bioinformatics and data management — networks) programmes. Policy-makers and other biomedical policy actors in Finland have made their country's participation in these initiatives an explicit priority (Academy of Finland 2009). FIMM also overlaps to a great extent with the Translational Genome-Scale Biology Centre of Excellence. The 15 Centres of Excellence are considered to support the cuttingedge of Finnish science, across all fields. TR projects at the institute include system biology approaches to cancer pathophysiology and treatment, diagnostic and pharmacogenomic test development using genomic profiling technologies, but also research into the genomic bases of a few groups of diseases.

Based on this research portfolio, FIMM is thus firmly positioned on the pre-clinical side of TR. Exchanges with clinicians and the provision of patient tissue samples, for example, are ensured through clinical cooperation groups. Nonetheless, one does not find here the kind of complex interdisciplinary experimental platforms integrating quasiindustrial systems for therapeutic development that are characteristic of the more ambitious proposals of the TR movement. Similarly, this centre is highly focussed on laboratorybased experiments, with no direct involvement of clinical experts or institutions within its structure.

Looking more broadly at the Finnish biomedical innovation system, the country is home to five faculties of medicine, each with their associated research hospital (Kuopio, Oulu, Helsinki, Tampere and Turku; Academy of Finland and Swedish Research Council 2009). In the 1990s, research campuses were built and attached to all of these university clinics, with the intention of stepping up multidisciplinary biomedical research activities. The local networks thus established were called Biocentres. The recent establishment of a competitive State subsidy funding system (EVO-funding) has also provided university clinics with additional funding for clinical research and training of physicians (Academy of Finland 2009). However, public sector reforms in the 1990s have decentralized competences towards municipalities (regional authorities), giving these authorities an internationally unprecedented level of competence and financial responsibility for health policy (Hakkinen and Lehto 2005). These municipalities have in turn had a tendency to take funds earmarked for research to finance clinical care (Academy of Finland 2009; The Science and Technology Policy Council of Finland 2008; Visakorpi 2009). So while the Finnish academic medical research sector seems to be facing institutional obstacles to the conduct of TR work, recent policy discussions have taken up the arguments of the TR narrative in efforts to reform local clinical research infrastructures. 


\section{Germany}

The Translational Research Alliance in Lower-Saxony (TRAIN) offers an interesting case to illustrate the development of TR activities in Germany. The initiative is explicitly concerned with developing new compounds. This aim is explicitly carried over in the shape of the collaboration and the members it includes. TRAIN regroups seven partners that all directly take part in various tasks and work packages of the collaboration's projects. These institutes are located in relative proximity within the two largest cities of the region. Founding members of the consortium are the Gottfried Wilhelm Leibniz Universität Hannover, the Fraunhofer Institute for Toxicology and Experimental Medicine (ITEM), the Hannover Medical School (MHH), the Helmholtz Centre for Infection Research (HZI), the Technische Universität Carolo-Wilhelmina zu Braunschweig and the University of Veterinary Medicine Hannover. An additional member of the consortium is the life sciences project management firm VPM. These founding members have launched a number of joint ventures that act as additional members of the consortium, including: Twincore, which brings together researchers from the Helmholtz Centre for Infection Research with large laboratory equipment for analyzing pharmaceutically active substances with clinicians and laboratory scientists with a clinical background from the nearby Hannover Medical School; the Centre for Biomolecular Drug Research, a screening and drug development facility and the forthcoming Clinical Research Center, linking capacities for early clinical trials to pre-clinical laboratory facilities. Also forthcoming is a Zentrum für Pharmaverfahrenstechnik (roughly translated as Centre for Pharmaceutical Process Engineering), which will take the pharmaceutical innovation and production process itself as an object of inquiry. In addition to this web of regional collaborations, the TRAIN consortium is a central node of the European Strategy Forum on Research Infrastructures (ESFRI) network European Advanced Translational Research Infrastructure in Medicine (EATRIS) network. The Helmholtz Centre for Infection Research is also the central node of the National Centre for Health Research focusing on infectious diseases. Based on the capacities that are being regrouped here, promoters of the consortium contend that it might well be possible to go from pre-clinical pathophysiological hypothesis to lead compound to early phase II trials entirely within the TRAIN partnership, with alliances with pharmaceutical industry planned for later phases of clinical testing, for regulatory approval and for commercialization. Through its member institutions, the consortium has access to a number of research teams working on the development of pre-clinical therapeutic hypotheses and interventions, using classical systems such as animal models, cell cultures and tissue collections. However, the consortium also has access to banks of natural compounds (HZI), mass compound screening equipment and expertise (HZI, Centre for Biomolecular Drug Research and Centre for Pharmaceutical Process Engineering), pharmacology and toxicology expertise (ITEM), skills in experimental medicine and clinical research (MHH and ITEM), facilities for the regulatory-compliant production and testing of new compounds (Centre for Biomolecular Drug Research, ITEM), as well as access to competences in strategic planning and coordination (VPM).

TRAIN thus closely resembles the prototypical consortium envisioned in TR models. It brings together a number of different but physically close centres of expertise with the hope that their capacities can combine and complement each other to allow advanced clinical development of new therapeutics within the public academic sector. Promoters of the consortium contend that the crisis in the pharmaceutical industry will vindicate their model, as firms in the sector would increasingly seek to "outsource" their R-D activities by tapping into academic development projects notably (interview with TRAIN coordinator). TRAIN also has strong clinical development components through the Hannover Medical School and the Fraunhofer Institute for Toxicology and Experimental Medicine (which both have clinical beds reserved for clinical studies, and with the first one having access to patients through its university clinics), although impetus for new project development does seem poised to originate more in individual laboratory projects rather than from clinical care and experimentation.

Germany has a large academic medicine sector, composed of 36 medical schools. The German medical schools captured 1.31 billion euros out of the 5.02 billion euros of third party research funds given out to the more than 100 German universities (MFT 2011). This represented $26 \%$ of this external funding pool. In 2001-2002, clinicians in German university clinics devoted $11 \%$ of their combined total work time to clinical or patient-oriented research (Wissenschaftsrat 2010). Nevertheless, reforms of Hochschulmedizin (academic medicine) in Germany to strengthen research capacity, and especially capacity to conduct patient-oriented biomedical research, have been recurring points of contention for national biomedical actors. Even before the policy discussion on the issue of TR emerged at the international level, the public funding agency for basic research (Deutsche Forschungsgemeinschaft, DFG) and the governmental advisory body German Council of Science and Humanities (Wissenschaftsrat) had issued a number of reports since the 1980 s which decried the adversary conditions for doing experimental medicine and clinical research in the German system of medical schools and academic hospitals (DFG 1999; Wissenschaftsrat 1986; Wissenschaftsrat 2004). The Wissenschaftsrat has often openly voiced criticism that German university clinics were not delivering research of a quality level that would be expected of them (Wissenschaftsrat 2010), that this research is taking place in relative isolation, between clinical or patient-oriented research and laboratory 
research within university clinics needed, but also between university clinics and other university and public institute (members of the four national research associations) laboratories. As in the case of Finland, the importance of these criticisms for the purpose of this analysis is to show how TR narratives have impacted or not broader efforts in institutional reform in Germany. A first observation here would thus be that emphasis on the vital role of clinical experimentation in biomedical innovation is not new to the TR agenda in Germany. Nonetheless, recent German policies have very much adopted the language of TR advocates when they defend the need for large-scale public networks with strong roles for clinical research centres. This can also be seen in another recent, major initiative by the German Federal Ministry of Education and Research (BMBF): the establishment of six National Centres for Health Research, consortia of university clinics linked to a core Helmholtz Centre (the Helmholtz Association of publicly financed research centres groups together 18 institutes that receive major support from the federal government, pursue long-term 'big science' goals that can contribute to overcoming societal 'grand challenges').

Training and human capital

\section{Austria}

Little activity could be observed in Austria in terms of specific training programmes to build human capital dedicated to TR, although the University of Vienna is currently developing relevant curriculum (Shahzad et al. 2011). Nonetheless, in parallel to the establishment of the ASC, the MUV has also worked to step up the scientific training of medical doctors, notably by making theses containing original experimental results a requirement of the programme. For established physicians, financial support for sabbaticals taken in laboratorybased research teams or in industry has also been increased, offering the possibility to develop towards a clinician-scientist career. Finally, recent funding programmes specifically target investigations informed by clinical situations and contexts that clinician-scientists are best positioned to lead (such as programmes for Clinical Research at the Austrian Science Fund; Patients in Focus at the ZIT, the technology promotion agency of the City of Vienna and the Vienna Science and Technology Fund's programme for the life sciences).

\section{Finland}

The Master's Degree Programme in Translational Medicine at the University of Helsinki is the main new training opportunity explicitly set up for TR in the country. The programme is aimed at biology or natural sciences students. The curriculum should familiarize these laboratory scientists with clinical practice and experimental medicine. The
Programme was initiated in the wake of broader reflections in the Finnish life sciences community about how little medical scientists were present within their own ranks, which made acquiring medical experience by typically laboratory-based researchers necessary. A important component of this discussion has been a 2008 survey of the clinical research landscape in the country conducted by the Academy of Finland. The authors of this inquiry concluded that career structures systematically discouraged medical students to pursue careers with a research component, and that clinical research more broadly was in decline in the country (Academy of Finland and Swedish Research Council 2009): between 2000 and 2007, the number of MDs trained per year had risen from around 350 to about 520 , while the number of $\mathrm{PhDs}$ awarded to holders of an MD had fallen from 210 to about 160 (Academy of Finland and Swedish Research Council 2009). The recent general strategy of the Academy of Finland has also picked up this theme, mentioning a need for increased support for clinician-scientists and for work on proof-of-concept in humans in therapeutic research. So while actual working conditions for clinician-scientists seem to be problematic, there appears to remain a desire within policy-makers and biomedical elites to improve support for the profession.

\section{Germany}

In comparison to Austria and Finland, Germany has seen a multiplication of educational programmes aimed specifically at training 'translational investigators'. These programmes typically provide further training in competences mobilized over the course of translational projects, such as aspects of laboratory and clinical research, regulatory affairs and project management. Examples are the International Research Graduate School for Translational Biomedicine (FIRST) at the Goethe University of Frankfurt; the Munich M4 Leading-Edge Cluster's Master of Science Translational Medicine; the University of Heidelberg's Master of Science in Translational Medical Research; the University of Leipzig's Centre for Clinical Trials' Master of Science Clinical Research and Translational Medicine and the Berlin-Brandenburg School for Regenerative Therapies' Clinical Scientist PhD programme (von Roth et al. 2011)

Increased support for investigators working both in experimental medicine and in the laboratory has also been promoted in the German health research policy. The Roadmap for Health Research and the Health Research Framework Programme, issued by the BMBF, both textually used the terms of "translational research", referred to the research areas the notions covered as important priorities and discussed problematic institutional situations for clinicianscientists as important obstacles to achieving a high performance in the area (BMBF 2007; BMBF 2010). 
Training programmes associated with TR efforts in Germany also go beyond clinician-scientists, however. For example, the future TRAIN Centre for Pharmaceutical Process Engineering will include its own training programme for "pharmaceutical engineers" as a career path distinct from pharmacology and revolving around the study and improvement of the drug innovation process itself.

\section{Coordination and policy}

\section{Austria}

Effective coordination of relevant actors had been achieved to varying degrees within different parts of the OncoTyrol and ASC consortia. While the OncoTyrol consortium has a substantial financial commitment from a large number of industrial partners, the latter do not seem to be actively involved in development projects together with the academic partners. Rather, the industry provides funds and some services and reagents, with the expectation that they stand a better chance to benefit from eventual 'breakthroughs'. The Section on Austrian experimental platforms for TR already reported that shared work between laboratory- and clinicbased actors at OncoTyrol did not always put the latter group of actors into the position of full contributors. Coordination at that level thus appears problematic. At another level, however, coordination was achieved through the consortium's strong central leadership, which ensured that only projects with high levels of short-term clinical relevance would obtain funding. At the ASC, in contrast, collaborations were deemed desirable but did not appear to be pursued to the same extent as in other cases reported on here. There appeared to be no leader with an overview of TR projects, and who might be in a position to attempt that most promising leads for new health interventions would be taken through pre-clinical and clinical development.

Recent Austrian biomedical policy has been primarily concerned with encouraging the formation of small- and medium-sized enterprises in the field of biotechnology. A comparatively broad amount of funding is made available to encourage early development and proof-of-concept research, as well as patenting through programmes such as BRIDGE from the Federal Ministry for Transport, Innovation and Technology, or Technology Marketing Austria and Life Science Austria from the Austrian Economy Service. The Translational Research Programme of the Austrian Science Fund (Fonds zur Förderung der wissenschaftlichen Forschung -FWF) has similar objectives, and addresses transfer activities from all fields of science. As such, various levels of the Austrian government have provided incentives to those academic and industry actors that elect to coordinate their innovation practices.
Recent discourse about TR now highlights the desirability of links between clinic and laboratory, especially in discussions about a "funding gap" between basic research (the field of the FWF) and applied research (usually funded by the Austrian Research Funding Agency). In the wake of these discussions, Austrian funding agencies are indeed changing their support policies. The aforementioned (section on Austrian experimental platforms) Clinical Research, Patients in Focus and Vienna Science and Technology Fund programmes do not yield large resources, but their existence testifies to the funding agencies' increasing belief that there are problems in the financial support structure for TR in the country. Such initiatives could contribute to intensified exchanges between groups from differing organisational and disciplinary backgrounds.

\section{Finland}

Participation in the national and international networks mentioned in Section "Finland" have appeared to be the main mechanism available for Finnish investigators interested in coordinating their experimental practices with those of colleagues in the goal of developing a new health intervention. The ESFRI consortia, most notably, each include a variety of complementary expertises, and are supported by teams of research coordinators and project managers. Finnish investigators may thus scale up their results and hypotheses into multi-national development projects through these networks.

\section{Germany}

The leaders of the TRAIN initiative opted to make dedicated coordinators and a firm specialised in product development central partners of their consortium. Here, questions of leadership, project continuity and efficient coordination of institutionally dispersed but complementary research teams are made central elements of the consortium's strategy. Nevertheless, in contrast to the OncoTyrol consortium, TRAIN does not have a central funding mechanism to support RTD work in itself, tying its coordinative capacity to principal investigators' willingness to receive support for their TR projects.

The recent federal Health Research Framework Programme offers a potential collective agenda for biomedical innovation that makes the speeding up of the translation of research results into industry-developed innovative products and processes a high priority. Privileged means to achieving this include the intensification of exchanges between actor groups from industry, laboratory-based academic contexts and clinic-based contexts. The concrete mechanisms expected to bring this programme into practice also denote a concern for increasing the strategic orientation of individual actors towards collaborative development work. Aside from the six German Health 
Research Centres, the policy draws on initiatives to support the achievement of methodological and ethical standards in clinical research and the integration of teams located at university clinics and fundamental research institutes in medical faculties (the Integrated Research and Treatment Centres and Clinical Study Centres support mechanisms, both launched in 2006). Another instrument seen as a component of these coordination efforts is the Pharmaceuticals Initiative from 2008, which provide a total of 100 million euros to three consortia that have a clear aim to engage in work that leads to the approval and commercialisation of new therapeutic modalities.

\section{Discussion}

Having reviewed the uptake of specific components of the TR model, it is now possible to discuss the degree of success that these propositions have encountered at a national level in each of our countries. This discussion segues into an evaluation of how institutional landscapes and policy traditions in Austria, Finland and Germany have shaped the reception of the TR model. Table 1 summarizes the findings presented in Section "Results" and forms the basis for this discussion.

In Austria, TR issues have often been narrowed to questions of technology transfer and academia-industry exchanges, with recent but modest initiatives aimed at bringing together clinical and laboratory teams. In general, Austrian policies have not made use of the TR model, and have not provided encouragements for actors from a variety of disciplinary and organisational backgrounds to come together to work on a single project. Elsewhere, the OncoTyrol initiative provides a clear example of the type of large-scale public consortium proposed in TR programmes. With its industry support and clear leadership, the consortium is poised to perform well as an "academic pipeline", although central integration of clinical expertise far enough to perfectly fit. The ASC stands in direct contrast with OncoTyrol, an initiative that is grounded in clinical contexts and able to directly tackle questions that may arise in daily care practices, but with no ambitions to mount complex development projects within its walls. This later conclusion is particularly supported by the absence of any central authority for the Centre. Research teams located there have retained their affiliations to their departments of origin (surgery, cardiology, paediatrics and so forth). The contrast between these two initiatives highlights the variety of paths through which clinic and laboratory can collaborate to create clinically useful innovation, whether these are complex new therapeutics to be marketed globally or new knowledge that allows local change in care practices. Austrian actors, however, do not seem to have taken up TR model components related to training and new means of coordinating biomedical innovation (with the exception of OncoTyrol for the latter).

Finland has historically developed outstanding competencies in genomics population research, and its science policy agencies actively encourage knowledge and technology transfer. Central claims of the TR movement, such as strengthening clinical research and supporting clinicianscientists have also been taken up in recent state policies. The TR model goal of strengthening of clinical experimentation and making it a central component of biomedical innovation was less in evidence at FIMM. Yet, through ESFRI networks extensive interdisciplinary and international collaborations have been established. These collaborations offer institutional settings for highly coordinated TR projects necessitating the participation of a number of different areas of technoscientific competence. The Master in Translational Medicine at the University of Helsinki is another measure which is indebted to the TR model. But there is otherwise little in the way of concrete provisions (as

Table 1 Overview of the impacts of the TR movement on the Austrian, Finnish and German biomedical innovation systems

\begin{tabular}{|c|c|c|c|}
\hline & Austria & Finland & Germany \\
\hline $\begin{array}{l}\text { Experimental platforms- } \\
\text { large-scale collaborations }\end{array}$ & OncoTyrol: yes; ASC: no & FIMM: no & TRAIN: yes \\
\hline $\begin{array}{l}\text { Experimental platforms- } \\
\text { strenghtening clinical } \\
\text { experimentation }\end{array}$ & $\begin{array}{l}\text { OncoTyrol: yes, but limited } \\
\text { ASC: yes, as a continuation } \\
\text { of previous commitments }\end{array}$ & $\begin{array}{l}\text { FIMM: no; broad efforts to } \\
\text { improve institutional support } \\
\text { for research in academic } \\
\text { medicine centres }\end{array}$ & $\begin{array}{l}\text { TRAIN: yes, but limited; broad } \\
\text { efforts to improve institutional } \\
\text { support for research in academic } \\
\text { medicine centres }\end{array}$ \\
\hline Training and human capital & $\begin{array}{l}\text { No dedicated training program; } \\
\text { small-scale financial support for } \\
\text { clinician-scientists starting } \\
\text { to be put into place }\end{array}$ & $\begin{array}{l}\text { One training programme; policy } \\
\text { concern to increase support for } \\
\text { clinician-scientists }\end{array}$ & $\begin{array}{l}\text { Multiple training programmes } \\
\text { with various foci; broad } \\
\text { concerns to increase support for } \\
\text { clinician-scientists }\end{array}$ \\
\hline Coordination and policy & $\begin{array}{l}\text { Multiple coordination initiatives } \\
\text { at the policy-level, oriented } \\
\text { towards academia-industry relations; } \\
\text { lacking coordination at project-level }\end{array}$ & $\begin{array}{l}\text { TR as clear policy goal; } \\
\text { interdisciplinarity through EU } \\
\text { networks; little support for } \\
\text { intra-national interdisciplinarity }\end{array}$ & $\begin{array}{l}\text { TR as clear policy goal; } \\
\text { coordination and business } \\
\text { management functions created at } \\
\text { project-level }\end{array}$ \\
\hline
\end{tabular}


opposed to policy discussions) that have aimed to strengthen national capacities in clinical experimental systems, or to train and support groups of professionals that might act as brokers and coordinators or TR projects.

Issues of integration and interaction between academia and industry or between clinical and laboratory contexts have been on Germany's actors' and health research policy agenda for some time, and German biomedical actors have taken active part in discussing the best way to improve TR capacities and proposing models and priorities at the policy level. German interventions for TR have been characterized by a number of large-scale initiatives revolving around the nation's established centres for large-scale research, the Helmholtz Institutes. At the same time, there has been a proliferation of smaller initiatives such as specialized Master's degrees or university institutes that have adopted the concepts of TR to represent their programmes. Germany thus holds many of the components that are advocated as privileged means to implement the TR model. The TRAIN consortium is, in our research, the closest example we have encountered to what one might imagine as an "academic drug pipeline". The consortium also involves novel practices of coordination and professional groups of brokers. These observations do not indicate that biomedical innovation systems in Germany are functioning smoothly. Many respondents to our interviews were dissatisfied with the continuing difficulties in mobilizing a range of actors for collaborations that cross boundaries. The establishment of the German Centres for Health Research has sparked discussions that national university clinics were being subordinated to centralised research administrations (Arbeitsgemeinschaft Hochschulmedizin 2011), showing that there can even be tensions between different components of the TR agenda (fostering large-scale collaborations and strengthening clinical research, in this case). Germany definitely appears to be the country in our small sample where the TR model has been most readily taken up. This applies for all components of the model, which is also in sharp contrast with what could be observed in Austria and Finland.

Given that TR is not a unified programme, countries have to select, adapt and modify those elements from the overall TR concept that are most appropriate for their goals, frame conditions and competencies. Whereas actors concerned with the innovation deficit in pharmaceutical industry might favour the establishment of large-scale collaborations in their arguments about the best way to organise national biomedical innovation systems (as the leaders of TRAIN have), other commentators have instead privileged the role for clinician-scientists in realising the TR agenda (as some Finnish and German policy-makers have). It seems possible to trace back this process of selection of certain components of the TR model to previous national developments. In Germany, the current level of attention devoted to clinician-scientists as privileged leaders of TR projects has been prepared by the Wissenschaftsrat's recommendations for improving academic medicine since 1984. This work predates the first uses of the terms "translational research" or "translational medicine", yet its more recent articulations seem to have co-evolved with the international trajectory of the TR movement. In Germany, this co-evolution has culminated recently in the establishment of the German Centres for Health Research. The federal government's rationale for the intervention takes up almost unmodified the Wissenschafsrat's contentions that university clinics ought to be closely networked with the nation's large number of non-university public institutes. The initiative's bid to fasten the mobilization of new biomedical knowledge in clinical innovation and align the innovation system towards patients needs seem directly inspired by the TR movement. The OncoTyrol consortium provides another interesting instance to study the interplay between the TR model and national idiosyncrasies in biomedical innovation. The make-up of this consortium can be traced back to local policy-makers' long-standing concerns with technology transfer and the support of academia-industry joint projects. An early version of the consortium was first assembled as a regional Center of Excellence, created with the explicit purpose of fostering academia-industry exchanges. Yet, in this case, the regional cluster involved not into an incubator of start-up biotechnology firms as national orientations may have indicated, but rather into an instance of TR large-scale development collaboration, with strong means to exert a broad coordination of individual research teams. Here again, propositions from the TR model have inflected local practices to create new organisational forms. In summary, important propositions from the TR model have certainly been implemented in the three countries studied. Yet previous institutional and policy developments have determined which components of the TR model have been taken up and which have not. Interestingly, whereas policy-makers in Finland and Germany appear to be key actors in the implementation of the TR model, uptake is driven very much by local biomedical leaders and academic administrations in Austria.

\section{Conclusion}

Translational research has emerged as a major new approach for the organisation of biomedical innovation systems. This article has sought to determine the extent to which the proposals of TR advocates have effectively been implemented in policy and new initiatives in Austria, Finland and Germany. From the results and discussion presented above, it appears that national TR initiatives in our three countries have developed very much in extension of historical trends and structures of biomedical RTD capacities. Local academic administrations and policy-makers have 
drawn mostly from those components of international TR initiatives and narratives that extend previous institutional and experimental trajectories. Germany has seen rather intensive institutional and policy activity revolving around the proposals of TR. Finland shows mixed adoption, although participation in EU networks offers a unique pattern of engaging in large collaborations for the development of complex new health interventions. Austria has seen the establishment of a few important initiatives but comparatively little policy activity. The TR programme of institutional and experimental reform thus remains one among many models available to inform efforts aimed at improving biomedical innovation systems.

\begin{abstract}
Acknowledgements We would like to thank Peter Biegelbauer and two anonymous reviewers for helpful comments on this paper.

The research presented in this paper has been accomplished within the TRi-GEN consortium financed by the ELSA-GEN joint programme of the Academy of Finland, the Austrian Ministry of Science and Research and the German Ministry of Education and Research. Etienne Vignola-Gagné is also supported by a doctoral scholarship of the Social Science and Humanities Research Council of Canada (grant \# 752-2010-0667).
\end{abstract}

Conflict of interest The authors declare that they have no conflict of interest.

Open Access This article is distributed under the terms of the Creative Commons Attribution License which permits any use, distribution, and reproduction in any medium, provided the original author(s) and the source are credited.

\section{Annex: List of interview respondents}

Austria

Interview 1

Two staff, FWF (Austrian Science Fund)

Interview in Vienna on September 21, 2010

Interview 2

Staff, AWS (Austrian Economy Service)

Interview in Vienna on September 23, 2010

Interview 3

Professor responsible for TR at the Medical University of Vienna

Interview in Vienna on October 19, 2010

Interview 4

Coordinator of a Cluster at the Ludwig-Boltzmann-Society

Interview in Vienna on October 29, 2010

Interview 5

CEO of a pharmaceutical company

Interview in Vienna on December 13, 2010

Interview 6

Joint Interview with a group leader and head of a "Core Facility" at the Anna Spiegel Center
Interview in Vienna on December 16, 2010

Interview 7

Expert on Health Technology Assessment, Ludwig-

Boltzmann-Society

Interview in Vienna on January 5, 2011

Interview 8

Group leader, Anna Spiegel Center

Interview in Vienna on December 9, 2011

Interview 9

Group leader, clinic of the Medical University of Vienna

Interview in Vienna on January 16, 2012

Finland

Interview 1

Two leaders of a training programme in Translational Medicine, University of Helsinki

Interview 2

Director of two translational genomics initiatives, University of Helsinki

Interview 3

Staff, Tekes, the Finnish Funding Agency for Technology and Innovation

Interview 4

Staff, Strategic Centre for Health and Welfare, the Federation of Finnish Technology Industries

Interview 5

Leader of research group working on the development of advanced therapeutic medicinal products in oncology, University of Helsinki

Germany

Interview 1

Professor, University Clinic Technical University Dresden Interview in Dresden on December 3, 2010

Interview 2

Staff, Centre for Clinical Studies, University Clinic Freiburg

Interview in Freiburg on May 25, 2011

Interview 3

Professor, University Clinic Erlangen

Interview per telephone on March 18, 2011

Interview 4

Staff, Twincore, Hannover

Interview in Hannover on October 29, 2010

Interview 5

Professor, Ludwigs-Maximillian University Clinic Munich and Helmholtz National Research Center for Health and Environment, Munich

Interview in Munich on March 30, 2011

Interview 6

Professor, Clinic Rechts der Isar, Technical University Munich

Interview in Munich on February 22, 2011

Interview 7 
Staff, Association of Research-Based Pharmaceutical Companies, Berlin

Interview in Berlin on January 5, 2011

Interview 8

Professor, University of Heidelberg, Medical Faculty Mannheim

Interview in Mannheim on December 20, 2010

Interview 9

Professor, German National Cancer Institute, Heidelberg

Interview in Heidelberg on January 11, 2011

Interview 10

Staff, Helmholtz National Research Center for Health and

Environment, Munich

Interview in Munich on March 30, 2011

Case Study Interview 11

Staff, VPM GmbH, Hannover

Interview in Hannover on December 13, 2011

Case Study Interview 12

Professor, Eberhard Karls University Clinic Tübingen

Interview in Tübingen on December 19, 2011

\section{References}

Academy of Finland (2009) Suomen tieteen tila ja taso 2009. Academy of Finland, Helsinki

Academy of Finland, Swedish Research Council (2009) Clinical Research in Finland and Sweden. Academy of Finland, Helsinki

Anonymous (2008) To thwart disease, apply now. Nature 453: 823

Anonymous (2012) What happened to personalized medicine? Nat Biotechnol 30(1): 1

Arbeitsgemeinschaft Hochschulmedizin (2011) Zentren für Gesundheitsforschung noch keine Erfolgsgeschichte. Press Release May 30, 2011. Arbeitsgemeinschaft Hochschulmedizin, Bonn.

Borstein SR, Licinio J (2011) Improving the efficacy of translational medicine by optimally integrating health care, academia and industry. Nat Med 17(12):1567-1569

Bundesministerium für Bildung und Forschung (BMBF) (2007) Roadmap for Health Research. Bundesministerium für Bildung und Forschung, Bonn, Berlin

Bundesministerium für Bildung und Forschung (BMBF) (2010) Health Research Framework Programme of the Federal Government. Bundesministerium für Bildung und Forschung, Bonn, Berlin

Calvert J (2010) Systems biology, interdisciplinarity and disciplinary identity. In: Parker JN, Vermeulen N, Penders B (eds) Collaboration in the new life sciences. Ashgate, Farnham, pp 201-218

Canadian Institutes of Health Research (2011) Canada's strategy for patient-oriented research. Canadian Institutes of Health Research, Ottawa

Coller BS (2008) Translational research: forging a new cultural identity. Mt Sinai J Med 75:478-487

Collins FS (2011) Reengineering translational science: the time is right. Sci Transl Med 3(90): $90 \mathrm{~cm} 17$.

Colyvas JA (2007) From divergent meaning to common practices: the early institutionalization of technology transfer in the life sciences at Stanford University. Res Policy 36:456-476

Corolleur CDF, Carrere M, Mangematin V (2004) Turning scientific and technological human capital into economic capital: the experience of biotech start-ups in France. Res Policy 33:631-642
Deutsche Forschungsgemeinschaft (DFG) (1999) Klinische Forschung. Denkschrift. Wiley-VCH, Weinheim

Ebers M, Powell WW (2007) Biotechnology: its origins, organization, and outputs. Res Policy 36:433-437

Fischer F (2003) Reframing public policy. Oxford University Press, Oxford

FitzGerald GA (2009) Moving clinical research in academic medical centres up the value chain. Nat Rev Drug Discov 8:597

Food and Drug Administration (FDA) (2004) Innovation or stagnation. Challenge and opportunity on the critical path to new medical products. U.S. Department of Health and Human Services, Washington, D.C

Gaisser S, Vignola-Gagné E, Hüsing B, Enzing C, van der Valk T (2009) EU policies in personalized medicine-related technologies. Personalized Med 6(1):93-102

Gottweis H (1998) Governing molecules. MIT press, Cambridge (Massachusetts) and London

Grimaldi R, Kenney M, Siegel DS, Wright M (2011) 30 years after Bayh-Dole: reassessing academic entrepreneurship. Res Policy 40 (8): 1045-1057

Guston DH (2000) Between politics and science. Cambridge University Press, Cambridge

Hakkinen U, Lehto J (2005) Reform, change and continuity in Finnish health care. J Health Polit Policy Law 30(1-2):79-96

Harrigan RS, Emery LM (2010) Translational leadership: new approaches to team development. Ethn Dis 20: S1-141-S1-145.

Hoelder S, Clarke PA, Workman P (2012) Discovery of small molecule cancer drugs: successes, challenges and opportunities. Mol Oncol 6:155-176

Hörig H, Marincola E, Marincola MF (2005) Obstacles and opportunities in translational research. Nat Med 11:705-708

Institute of Medicine (2009) In: Sarah H, Lori N, Bruce Altevogt R (eds) Venture philanthropy strategies to support translational research: workshop summary. The National Academies Press, Washington, DC

Janssens ACJW, van Duijn CM (2010) An epidemiological perspective on the future of direct-to-consumer personal genome testing. Investig Genet 1(1):10

Keating P, Cambrosio A (2012) Cancer on trial. Oncology as a new style of practice. University of Chicago Press, Chicago

Khoury MJ, Gwinn M, Yoon PW, Dowling N, Moore CA, Bradley L (2007) The continuum of translational research in genomic medicine: how can we accelerate the appropriate integration of human genome discoveries into health care and disease prevention? Genet Med 9(10):665-674

Kupferschmidt K (2011) Germany clambers aboard translational research bandwagon. Can Med Assoc J 183:E219-E220

Lander B, Atkinson-Grosjean J (2011) Translational science and the hidden research system in universities and academic hospitals: a case study. Soc Sci Med 72:537-544

MacIlwain C (2011) Pharmaceutical industry must take its medicine. Nature 470:141

Marincola FM (2011) The trouble with translational medicine. J Intern Med 270:123-127

Martin P, Hopkins MM, Nightingale P, Kraft A (2009) On a critical path: genomics, the crisis of pharmaceutical productivity and the search for sustainability. In: Atkinson P, Glasner P, Lock M (eds) Handbook of genetics and society. Routledge, London, pp 145-162

Medizinischer Fakultätentag (MFT) (2011) Forschungsleistungen in der Medizin wiederum angestiegen. Press Release. Medizinischer Fakultätentag, Berlin

Milne C-P, Kaitin KI (2009) Translational medicine: an engine of change for bringing new technology to community health. Sci Transl Med 1(5): $5 \mathrm{~cm} 5$.

Mittra J, Tait J, Wield D (2011) The future of pharmaceutical innovation: new challenges and opportunities. Innov Pharm Technol March 2011:32-34 
Morgan M, Barry CA, Donovan JL, Sandall J, Wolfe CD, Boaz A (2011) Implementing 'translational' biomedical research: convergence and divergence among clinical and basic scientists. Soc Sci Med 73:945-952

Nathan DG (2002) Careers in translational clinical research-historical perspectives, future challenges. JAMA 287:2424-2427

National Cancer Institute (NCI) (2007) Transforming translationharnessing discovery for patient and public benefit. Report of the Translational Research Working Group of the National Cancer Advisory Board. National Cancer Institute, Bethesda

Nightingale P, Martin P (2004) The myth of the biotech revolution. Trends Biotechnol 22(11):564-569

Nowotny N, Scott P, Gibbons M (2001) Rethinking science. Polity Press, Cambridge

Pisano G (2006) Science business: the promise, the reality, and the future of biotech. Harvard Business School Press, Boston

Schmidt VA (2012) Discursive institutionalism: scope, dynamics, and philosophical underpinnings. In: Fischer F, Gottweis H (eds) The argumentative turn revisited. Duke University Press, Durnham, pp 85-114

Shahzad A, McLachlan C, Gault J, Cohrs R, Wang X, Köhler G (2011) Global translational medicine initiatives and programs. Transl Biomed 2(3):2

Silber BM (2010) Driving drug discovery: the fundamental role of academic labs. Sci Transl Med 2(30): $30 \mathrm{~cm} 16$.

Stuart TE, Ozdemir SZ, Ding WW (2007) Vertical alliance networks: the case of university-biotechnology-pharmaceutical alliance chains. Res Policy 36:477-498

Swinney DC, Anthony J (2011) How were new medicines discovered? Nat Rev Drug Discov 10:507-519

The Science and Technology Policy Council of Finland (2008) Review 2008. Science and Technology Policy Council of Finland, Helsinki

Trippl M, Todtling F (2008) From the ivory tower to the marketplace: knowledge organisations in the development of biotechnology clusters. J Regional Analysis Policy 38(2):159-175

Van der Weijden I, Maaike V, van den Besselaar P (2012) From bench to bedside: the societal orientation of research leaders: the case of biomedical and health research in the Netherlands. Sci Public Policy 39:285-303
Visakorpi T (2009) Lääketieteellisen tutkimuksen rakenteet Suomessa. Mitä on translationaalinen lääketiede? Pääkirjoitus. Duodecim 125(21): 2308-2309.

Von Roth P, Canny BJ, Volk H-D, Noble JA, Prober CG, Perka C, Duda GN (2011) The challenges of modern interdisciplinary medical research. Nat Biotechnol 29(12):11451148

Wainwright SP, Williams C, Michael M, Cribb A (2009) Stem cells, translational research and the sociology of science. In: Atkinson P, Glasner P, Lock M (eds) Handbook of genetics and society. Routledge, London, pp 41-58

Wehling M (2008) Translational medicine: science or wishful thinking? J Transl Med 6:31

Wehling M (2010) Principles of translational science in medicine. Cambridge University Press, Cambridge

Weissmann G (2005) Roadmaps, translational research, and childish curiosity. FASEB J 19:1761-1762

Williams RJ, Walker I, Takle AK (2012) Collaborative approaches to anticancer drug discovery and development: a cancer research UK perspective. Drug Discov Today 17:185-187

Wilson-Kovacs DM, Hauskeller C (2012) The clinician-scientist: professional dynamics in clinical stem cell research. Sociol Health Illn 34(4):497-512

Wissenschaftsrat (1986) Empfehlungen zur klinischen Forschung in den Hochschulen. Wissenschaftsrat, Köln

Wissenschaftsrat (2004) Empfehlungen zu forschungs- und lehrförderlichen Strukturen in der Universitätsmedizin. Wissenschaftsrat, Köln

Wissenschaftsrat (2010) Empfehlungen zur Weiterentwicklung der ambulanten Universitätsmedizin in Deutschland. Wissenschaftsrat, Köln

Woolf SH (2008) The meaning of translational research and why it matters. JAMA 2999(2):211-213

Yap TA, Sandhu SK, Workman P, de Bono JS (2010) Envisioning the future of early anticancer drug development. Nat Rev Cancer 10:514-523

Zerhouni EA (2005) Translational and clinical science - time for a new vision. N Engl J Med 353:1621-1623 